\title{
SUMBERDAYA IKAN KEMBUNG \\ (Rastrelliger kanagurta Cuvier 1817) DI PERAIRAN SELAT SUNDA YANG DIDARATKAN DI PPP LABUAN, BANTEN
}

\author{
Resources of Indian Mackerel (Rastrelliger kanagurta Cuvier 1817) \\ in Sunda Strait Water that Landed on PPP Labuan, Banten
}

Oleh:

\author{
Viska Donita Prahadina1*, Mennofatria Boer², Achmad Fahrudin² \\ 1 Program Studi Pengelolaan Sumberdaya Pesisir dan Lautan, Sekolah Pascasarjana Institut Pertanian Bogor \\ 2 Departemen Manajemen Sumberdaya Perairan, Fakultas Perikanan dan Ilmu Kelautan, Institut Pertanian Bogor
}

*Korespondensi: viiiskaaa@gmail.com

Diterima: 31 Agustus 2015; Disetujui: 03 November 2015

\begin{abstract}
Indian mackerel is one of the small pelagic fish that has an important economic value and the dominant fish catches landed in PPP Labuan. The catch of Indian mackerel decreaseyear to year. Therefore Indian mackerel resources, alleged have over-exploited. The aim of this research was to identify a production pattern, fishing ground, fishing season pattern and identify a more appropriate alternative recommendation for the management of Indianmackerel. The results showedthat the production of Indian mackerel had a fluctuated seasonal pattern. The peak fishing season was in April to August while low season (low catches) in December and January. Distribution of Indian mackerel fishing grounds wasin the waters around the Sunda Strait such as Rakatalsland, Rakata Kecil Island, Anak Rakatalsland, Panaitan Island, Papole Island, Sebesi Island, Sebuku Island, Jongor and Tanjung Lesung. Utilization status of Indian mackerel has already overfished in biology and economics. Some recommendation for managing Indian mackerel resources that were landed in PPP Labuan such as, reduce the fishing effort, increase the mesh size, and improvementmanagement infishing season and fishing ground.
\end{abstract}

Keywords: Indian mackerel, management, PPP Labuan, Sunda Strait

\begin{abstract}
ABSTRAK
Ikan kembung merupakan salah satu ikan pelagis kecil yang memiliki nilai ekonomis penting dan merupakan ikan tangkapan dominan yang didaratkan di PPP Labuan. Hasil tangkapan ikan kembung menurun dari tahun ke tahun. Oleh sebab itu diduga ikan kembung telah mengalami eksploitasi berlebih. Tujuan penelitian ini adalah untuk mengetahui pola produksi, daerah tangkapan, pola musim penangkapan, serta mengidentifikasi alternatif pengelolaan yang lebih tepat. Hasil penelitian menunjukkanbahwa pola produksi ikan kembung berfluktuatif. Musim puncak penangkapan ikan berada pada bulan April hingga Agustus, sedangkan musim paceklik berada pada bulan Desember dan Januari. Sebaran wilayah penangkapan berada di sekitar perairan Selat Sunda seperti di P. Rakata, P. Rakata Kecil, P. Anak Rakata, P. Panaitan, P. Papole, P. Sebesi, P. Sebuku, Jongor serta Tanjung Lesung. Pengelolaan ikan kembung dapat dilakukan dengan cara mengurangi upaya penangkapan, memperbesar ukuran mata jaring, pengaturan musim penangkapan dan daerah penangkapan.
\end{abstract}

Kata kunci: ikan kembung, pengelolaan, PPP Labuan, Selat Sunda 


\section{PENDAHULUAN}

Selat Sunda merupakan salah satu perairan di Indonesia yang memiliki potensi ikan pelagis yang cukup tinggi yaitu lebih dari 25.000 ton/tahun. Salah satu daerah yang berbatasan langsung dengan Selat Sunda adalah Kabupaten Pandeglang dengan 1 unit PPP (Pelabuhan Perikanan Pantai), yaitu PPP Labuan dan 7 unit TPI. Wilayah Kabupaten Pandeglang memiliki panjang garis pantai $230 \mathrm{~km}$ yang terletak di ujung barat dari Provinsi Banten. Batas administrasi wilayah ini sebelah utara adalah Kabupaten Serang, sebelah selatan Samudera Hindia, sebelah barat Selat Sunda dan sebelah timur Kabupaten Lebak. Luas perairan di Kabupaten Pandeglang $\pm 1.700 \mathrm{~km}^{2}$ dengan pengelolaan laut sejauh 4 mil. Kabupaten Pandeglang memiliki kemudahan akses ke beberapa perairan seperti Laut Jawa dan Selat Sunda, serta Samudera Hindia. Keadaan tersebut menunjukkan bahwa Kabupaten Pandeglang memiliki peluang yang cukup besar dalam pengembangan usaha perikanan. Daerah yang memiliki potensi besar di sektor perikanan salah satunya adalah Kecamatan Labuan.

Sebagian besar ikan hasil tangkapan di perairan Selat Sunda didaratkan di Kabupaten Pandeglang yaitu di PPP Labuan.Secara geografis PPP Labuan berada di sebelah utara Kabupaten Pandeglang dan terletak di Desa Teluk, Kecamatan Labuan. PPP Labuan berada pada posisi koordinat $06^{\circ} 24^{\prime} 30^{\prime \prime}$ 'LS dan $105^{\circ} 49^{\prime} 15^{\prime \prime}$ BT. PPP Labuan terdiri atas TPI 1 dan TPI 3 yang berada di muara Sungai Cipunteun, serta TPI 2 berada di tepi pantai terbuka. PPP Labuan berada di sekitar wilayah perairan pesisir yang cukup potensial menghasilkan sumberdaya ikan pelagis kecil yaitu ikan kembung. Ikan kembung yang didaratkan di PPP Labuan terdiri dari dua spesies yaitu ikan kembung lelaki (Rastrelliger kanagurta) dan ikan kembung perempuan (Rastrelliger brachysoma).

Ikan kembung merupakan salah satu ikan pelagis kecil yang sangat potensial dan ditemukan hampir di seluruh perairan Indonesia. Ikan kembung merupakan ikan yang memiliki nilai ekonomis penting. Hal ini disebabkan ikan tersebut paling banyak ditangkap untuk dikonsumsi oleh sebagian besar masyarakat Labuan bila dibandingkan dengan ikan pelagis lainnya. Nilai ekonomi yang tinggi pada ikan kembung mengakibatkan nelayan Labuan cenderung melakukan penangkapan secara berlebih tanpa memperhatikan aspek biologi ikan tersebut. Keberadaan sumberdaya ikan kembung di Selat Sunda sangat penting baik secara ekologis maupun ekonomis. Namun pada tahun 2011-
2013 terjadi penurunan CPUE dari 1.00 ton/trip menjadi 0.69 ton/trip sehingga dikhawatirkan telah terjadi tangkap lebih pada sumberdaya ikan kembung (Dinas Kelautan dan Perikanan Kabupaten Pandeglang 2013). Pemanfaatan ikan kembung yang tidak dikontrol akan mengancam kelestarian atau kepunahan bagi sumberdaya ikan kembung di masa mendatang. Agar tingkat eksploitasi sumberdaya ikan kembung di perairan Selat Sunda lebih terkonrol, maka perlu dilakukan analisis sumberdaya ikan kembung agar sumberdaya tersebut tetap lestari. Berdasarkan latar belakang tersebut, penelitian ini dilakukan dengan tujuan untuk memberikan informasi mengenai produksi ikan kembung, mengidentifikasi wilayah sebaran sumberdaya ikan kembung di perairan sekitar Labuan, mengidentifikasi pola musim penangkapan, dan mengidentifikasi model pengelolaan ikan kembung tersebut.

\section{METODE}

Penelitianinidilakukan di PPP Labuan, pada bulan Maret hingga Mei 2014.lkan-ikan yang didaratkan di PPP Labuan merupakan ikan-ikan yang pada umumnya ditangkap oleh para nelayan di perairan Selat Sunda. Daerah penangkapan ikan bagi nelayan-nelayanyang berbasis di PPP Labuan disajikan pada Gambar1. Alat tangkap yang digunakan adalah purse seine, bagan, payang, dogol, jaring rampus, dan pancing.

Data yang digunakan dalam penelitian ini adalah data primer dari hasil wawancara dengan nelayan dan data sekunder. Data primer diperoleh dari wawancara dengan nelayan yang menangkap ikan kembung, dengan menggunakan metode purposive sampling yaitu didasarkan atas pertimbangan peneliti bahwa unsur-unsur yang dikehendaki telah ada di dalam contoh yang telah diambil. Adapun data mengenai hasil tangkapan, alat tangkap, harga ikan, dan trip ikan kembung diperoleh dari Dinas Kelautan dan Perikanan Pandeglang dan kantor Tempat Pendaratan Ikan Labuan tepatnya di TPI 2 sebagai tempat pendaratan ikan kembung.Tujuan dilakukan wawancara adalah untuk mendapatkan informasi mengenai alat tangkap, ukuran mata jaring, ukuran kapal, hasil tangkapan, biaya operasi dan pendapatan.

Analisis data dilakukan dengan menggunakan analisis spasial, pola musim penangkapan ikan serta analisis CPUE dan RPUE. Analisis spasial merupakan analisis yang digunakan untuk mengetahui sebaran daerah penang-kapan ikan kembung yang didaratkan di PPP Labuan. Langkah-langkah yang dilaku- 
kan untuk menentukan daerah sebaran penangkapan ikan kembung adalah sebagai berikut:

1) Penentuan banyaknya jumlah responden (nelayan yang akan diwawancara mengenai daerah penangkapan ikan kembung berdasarkan alat tangkap yang digunakan).

2) Pembuatan peta dasar dari lokasi penelitian.

3) Pembuatan plot-plot lokasi penangkapan ikan kembung dalam bentuk spasial ke peta dasar, berdasarkan data dari parcipatory approach.

4) Formulasipetadaerahpenangkapan.

Analisis pola musiman ikan kembung di sekitar perairan Selat Sunda digunakan sebagai pertimbangan dalam melakukan operasi penangkapan ikan (Mehanna 2001). Indeks musim penangkapan dihitung dengan menggunakan data CPUE dari data bulanan ikan kembung. Data bulanan diurutkan dari tahun 2003 sampai tahun 2013, setelah itu dihitung dengan metode rata-rata bergerak. Menurut Dajan (1986) in Harjanti et al. (2012), rumus untuk mendapatkan rata-rata bergerak adalah sebagai berikut:

$$
I M P i=R R B i \times F K
$$

Keterangan:

$I M P_{i}$ : Indeks musim penangkapan bulan ke- $i$

$R B B_{i}$ : Rasio rata-rata untuk bulanan ke-i

I $: 1,2,3, \ldots, 12$

FK : Faktor koreksi

Analisis CPUE dan RPUE bertujuan untuk melihat apakah ada alokasi upaya penangkapan yang berdasarkan pada keuntungan atau pendapatan yang akan diperoleh. Keuntungan ini dilihat dari nilai pasar sebuah komoditas atau jumlah produksi. Peramalan keuntungan ekonomi ini tidak bisa dihitung secara langsung tetapi bisa diestimasi dengan hitungan bio income atau Revenue per unit Effort (RPUE), seperti yang dikemukan oleh Bene and Tewfik (2000) in Khoiriya (2010) sebagai berikut:

$$
R P U E \mathrm{j}=\frac{C P U E j}{p j} \text { dan } C P U E \mathrm{j}=\frac{C j}{E j}
$$

Keterangan :

Cj : Hasil tangkapan pada tahun ke-j

Ej : Upaya penangkapan pada tahun ke-j

RPUEj : Pendapatan per upaya pada tahun-j

CPUEj : Hasil tangkapan per upaya pada tahun-j

pj : Harga pada tahun ke-j

\section{HASIL}

Ikan-ikan yang dominan didaratkan di PPP Labuan adalah jenis ikan pelagis dan demersal. Ikan kembung merupakan ikan dengan hasil tangkapan terbanyak di PPP Labuan. Persentase hasil tangkapan ikan kembung di PPP Labuan sebesar $13 \%$ dari total tangkapan keseluruhan pada tahun 2013. Alat tangkap utama yang digunakan untuk menangkap ikan kembung berdasarkan hasil wawancara dengan nelayan adalah jaring rampus dengan ukuran mata jaring2 inchi dan purse seine. Jaring rampus dioperasikan menggunakan kapal motor berukuran 2-6 GT dan purse seine dioperasikan dengan menggunakan kapal berukuran 12-15 GT. Produksi dan upaya penangkapan ikan kembung dari tahun 2003-2013 disampaikan pada Gambar 2.

Berdasarkan Gambar 2, terlihat bahwa produksi serta upaya penangkapan ikan kembung mengalami fluktuasi tiap tahunnya. Hal ini dikarenakan produksi dipengaruhi oleh banyak faktor selain upaya penangkapan, diantaranya tenaga kerja, kelimpahan sumberdaya ikan, dan permodalan (Panayotou 1982). Produksi tertinggi terjadi pada tahun 2003, sedangkan produksi terendah terjadi pada tahun 2013.

Gambar 3 menunjukkan pola keterkaitan antara CPUE (Catch per Unit Effort) dan RPUE (Revenue per Unit Effort). Berdasarkan gambar tersebutdapat dilihat bahwa nilai CPUE dan RPUE yang terjadi pada ikan kembung berbanding lurus. Hal ini disebabkan permintaan pasar yang tinggi terhadap ikan kembung. Nilai RPUE yang mengikuti CPUE menandakan bahwa harga ikan kembung cenderung stabil, artinya pergerakkan harga ikan kembung mengikuti hasil tangkapan dan upaya penangkapan ikan kembung. Harga ikan kembung di PPP Labuan cenderung mengikuti hukum pasar, dimana pada saat produksi menurun maka harga ikan kembung akan meningkat.

Analisis pola musim penangkapan ikan kembung di Selat Sunda menggunakan pendekatan metode rata-rata bergerak untuk menghitung nilai Indeks Musim Penangkapan (IMP) pada setiap bulannya sehingga membutuhkan data bulanan CPUE (Gambar 4).

\section{PEMBAHASAN}

Ikan kembung yang didaratkan di PPP Labuan ada dua jenis yaitu ikan kembung lelaki (Rastrelliger kanagurta) dan ikan kembung perempuan (Rastrelliger brachysoma). Kedua ikan kembung ini berasal dari genus yang sama, ciri yang membedakannya adalah adanya 


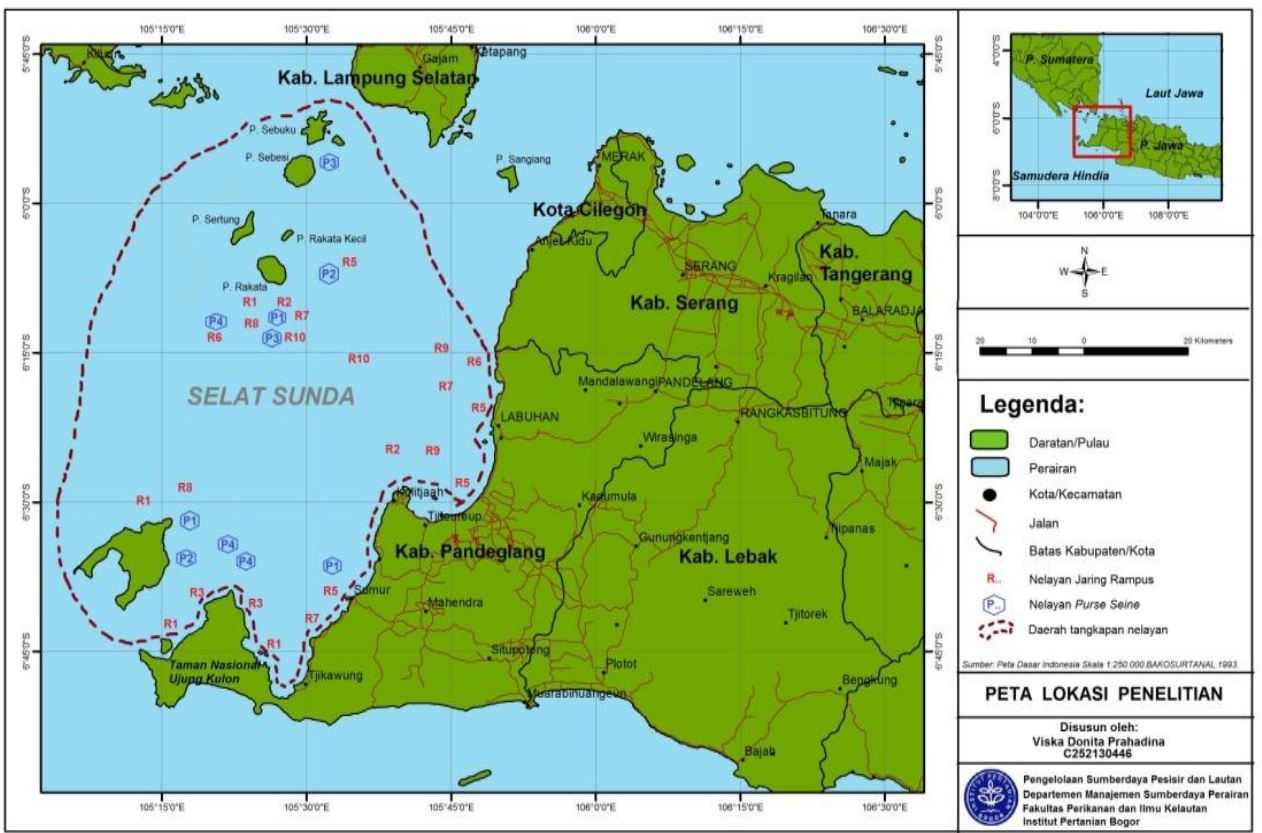

Gambar 1 Lokasi penelitan

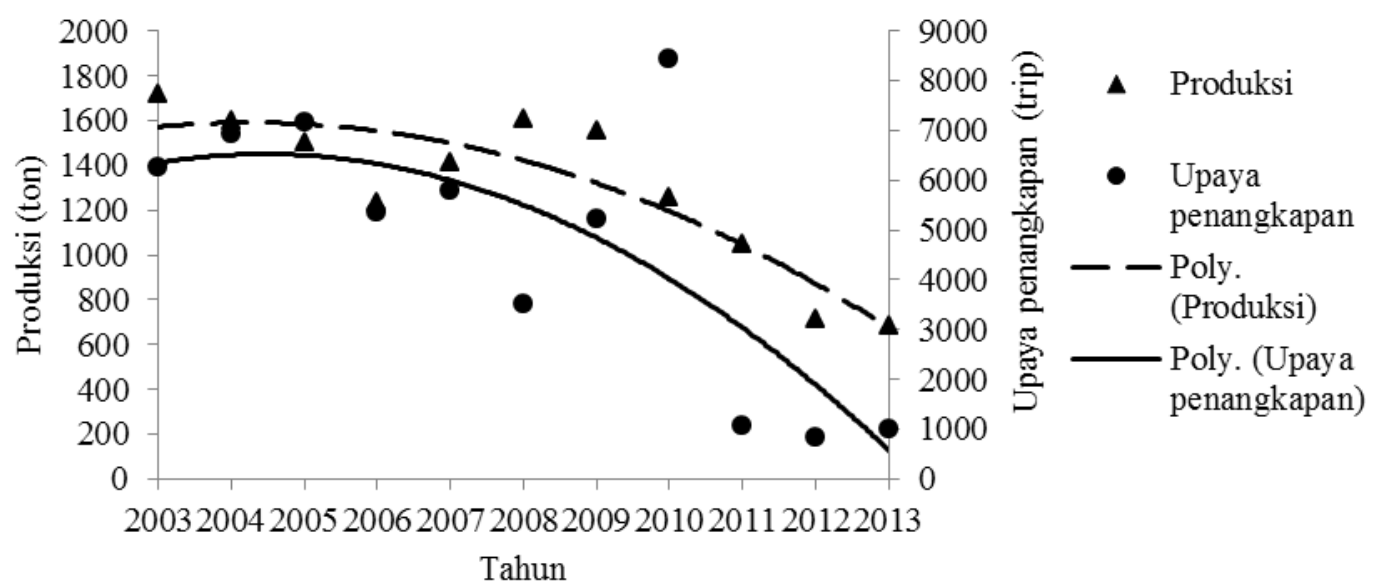

Gambar 2 Pola produksi dan upaya penangkapan ikan kembung

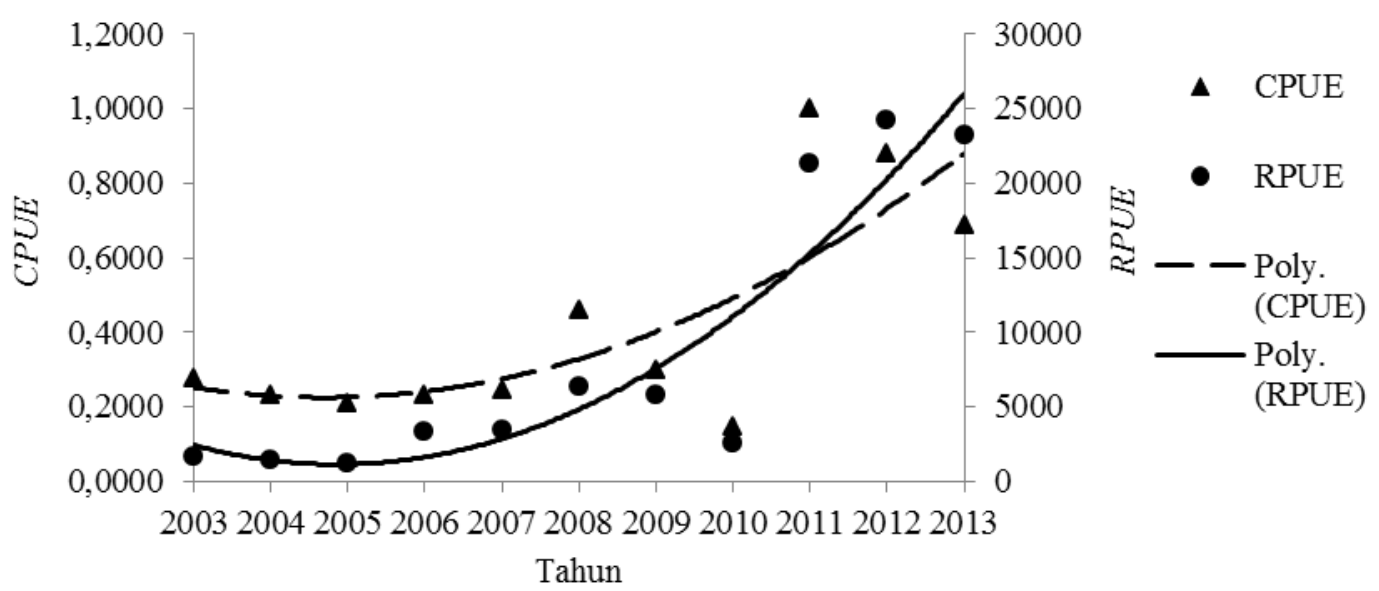

Gambar 3 Keterkaitan antara CPUE dan RPUE 


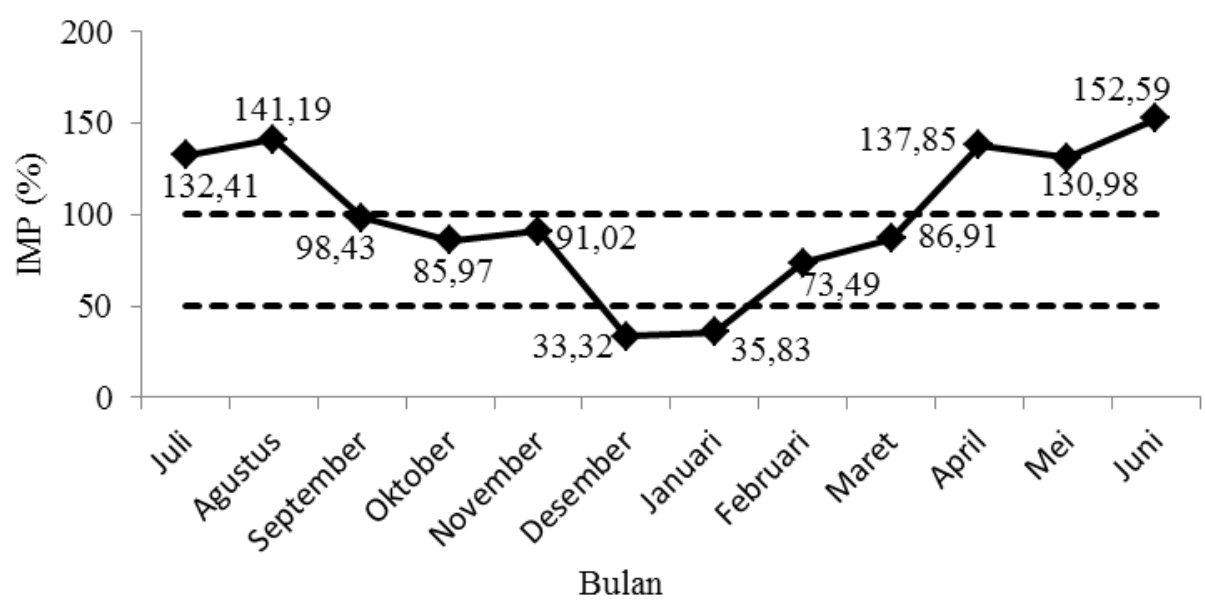

Gambar 4 Nilai indeks musim penangkapan ikan kembung

satu bintik atau totol hitam dekat sirip dada pada ikan kembung lelaki. Selain itu, ikan kembung perempuan memiliki perut yang lebih lebar dibandingkan ikan kembung lelaki dan bola mata ikan kembung perempuan lebih besar dibanding ikan kembung lelaki. Kedua ikan tersebut telah diidentifikasi menurut Saanin (1984). Menurut Al-Zibdah M dan N Obat (2007) famili scombridae, mackerel, dan tuna merupakan sumberdaya perikanan komersial yang penting di dunia. Ikan kembung hampir setiap bulan didaratkan di PPP Labuan. Hal ini disebabkan ikan kembung merupakan ikan ekonomis penting. Harga jual dari ikan kembung lelaki berkisar Rp 20.000-Rp 30.000 per $\mathrm{kg}$ sedangkan untuk ikan kembung perempuan berkisar Rp 23.000-Rp 26.000 per $\mathrm{kg}$.

Menurut Utami et al. (2012) produksi ikan setiap tahunnya dapat mengalami fluktuasi. Hal ini wajar karena produksi ikan tidak hanya dipengaruhi oleh banyaknya upaya penangkapan yang dilakukan, tetapi juga dipengaruhi oleh faktor-faktor lain seperti tenaga kerja, kelimpahan sumberdaya ikan, dan permodalan. Hasil wawancara dengan nelayan di Labuan menunjukkan bahwa daerah penangkapan ikan kembung berada di sekitar P.Rakata, P.Rakata Kecil, P. Anak Rakata, P. Panaitan, P. Papole, P. Sebesi, P. Sebuku, Jongor serta Tanjung Lesung. Jarak tempuh antara daerah penangkapan dengan PPP Labuan berkisar 3-4 jam perjalanan. Gambar 1 menunjukkan bahwa daerah penangkapan ikan kembung hanya berada di sekitar pantai pulaupulau di perairan Selat Sunda. Menurut ne- layan di Labuan, musim puncak penangkapan ikan kembung terjadi pada bulan April sampai Agustus. Daerah penangkapan pada bulan tersebut di sekitar Pulau Rakata, Pulau Panaitan, Tanjung Lesung dan Sumur. Musim paceklik ikan kembung terjadi pada bulan Desember hingga Januari. Hal ini sesuai dengan nilai IMP yang diperoleh. Analisis pola musim penangkapan bertujuan untuk melihat musim atau waktu penangkapan yang tepat bagi ikan kembung sehingga dapat digunakan sebagai pertimbangan dalam operasi penangkapan ikan.

Prediksi keuntungan ekonomi tidak dapat dihitung secara langsung tetapi dapat diestimasi melalui perhitungan pendapatan per trip upaya (RPUE). Adapun untuk mendapatkan nilai RPUE menggunakan data catch per unit effort (CPUE) per tahun dan menggunakan data harga. Data CPUE dan harga ikan yang digunakan berasal dari data sekunder per tahun.

Rencana pengelolaan yang dapat dilakukan berdasarkan hasil kajian diantaranya adalah perlu adanya pengurangan upaya penangkapan agar didapatkan keuntungan yang maksimum, namun tetap mengarah kepada penangkapan ikan yang sudah berukuran besar (sudah pernah mengalami matang gonad). Menurut Yusuf et al. (2007) permasalahan teknis dan sosial akan muncul, khususnya pada pengalihan keahlian. Permasalahan teknis seperti kesulitan dalam hal keterampilan apabila dia- 
lihkan pada kegiatan lain, mengingat teknik penangkapan yang berbeda sehingga membutuhkan pembelajaran dan waktu untuk beradaptasi. Permasalahan sosial terjadi apabila kebijakan pengurangan nelayan melalui relokasi, maka akan membutuhkan waktu lebih lama untuk beradaptasi dengan lingkungan yang baru. Perbedaan latar belakang budaya masyarakat biasanya selalu menjadi hambatan sehingga para pengambil kebijakan perlu memahami secara mendalam tipologi masyarakat nelayan yang akan direlokasi dan tipologi masyarakat di daerah relokasi.

Selain itu perlu dilakukan pengaturan ukuran mata jaring khususnya alat tangkap purse seine yang menjadi alat tangkap dominan dalam menangkap ikan kembung. Pendekatan selektivitas melalui regulasi ukuran mata jaring dilakukan agar ukuranukuran ikan yang belum matang gonad, sedang dalam proses kematangan dan sedang matang gonad tidak tertangkap. Oleh karena itu ukuran ikan yang tertangkap diharapkan melebihi ukuran pertama kali matang gonad (Boerdan Kiagus 2007). Budimawan et al. (2004) menyatakan bahwa ukuran pertama kali matang gonad merupakan indikator ketersediaan stok reproduktif. Hal lain yang dapat dilakukan adalah penutupan sementara daerah penangkapan pada bulan yang diduga menjadi periode pemijahan ikan kembung (Sulistiono 2006). Langkah ini dilakukan untuk memberikan waktu kepada sumberdaya ikan untuk pulih kembali sehingga kapasitas yang optimal dan lestari dapat tercapai kembali (Stregiou 2000). Agar tidak terjadi masalah baru maka dibutuhkan kerjasama antara pemerintah sebagai pembuat kebijakan dan pengelola, masyarakat khususnya nelayan serta pihak yang terkait untuk memahami pentingnya kebijakan ini dalam meningkatkan kesejahteraan masyarakat nelayan ke depannya (Fauziyah dan Jaya 2010). Penutupan bulan penangkapan diduga dapat menurunkan hasil tangkapan nelayan. Oleh karena itu, nelayan perlu mengkonsentrasikan penangkapan terhadap jenis ikan lainnya yang belum mengalami tangkap lebih (Kekenusa 2008).

\section{KESIMPULAN}

Produksi ikan kembung di PPP Labuan berfluktuasi setiap bulannya, dikarenakan perbedaan lama trip saat melakukan penangkapan. Sebaran wilayah penangkapan ikan kembung berada di sekitar perairan Selat Sunda seperti di P. Rakata, P. Rakata Kecil, P. Anak Rakata, P. Panaitan, P. Papole, P. Sebesi, P. Sebuku, Jongor serta Tanjung Lesung. Musim puncak penangkapan ikan kembung yang didaratkan di PPP Labuan berada pada bulan April hingga Agustus sedangkan musim paceklik ikan kembung berada pada bulan Desember dan Januari. Pengelolaan sumberdaya ikan kembung yang didaratkan di PPP Labuan dapat dilakukan dengan cara mengurangi upaya penangkapan, memperbesar ukuran mata jaring purse seine, pengaturan musim penangkapan, dan pengaturan daerah penangkapan.

\section{SARAN}

Saran yang dapat diberikan untuk penelitian selanjutnya berdasarkan penelitian ini adalah perlu pengambilan contoh ikan yang mewakili musim paceklik (Desember dan Januari) agar dapat memberikan informasi lebih mengenai kondisi ikan kembung sehingga dapat menentukan alternatif pengelolaan yang lebih tepat dan berkelanjutan.

\section{DAFTAR PUSTAKA}

Al-Zibdah M, N Obat. 2007. Fishery status, growth, reproduction biology and feeding habit of two scombrid fish from the Gulf of Aqaba, Red Sea. Lebanese Science Journal. 8(2).

Boer M, Kiagus A Z. 2007. Gejala tangkap lebih perikanan pelagis kecil di Perairan Selat Sunda. Jurnal Ilmu-ilmu Perairan dan Perikanan Indonesia. 14(2):167-172.

Budimawan, Indar MYN, Mallawa A, Najamuddin. 2004. Pendugaan ukuran pertama kali matang gonad ikan layang deles (Decapterus macrosoma Bleeker). Jurnal Sains dan Teknologi. 4(1) : 1-8.

Dinas Kelautan dan Perikanan Kabupaten Pandeglang. 2013. Statistik Perikanan Tangkap Kabupaten Pandeglang Tahun 20032013.

Fauziyah, Jaya A. 2010. Densitas Ikan Pelagis Kecil Secara Akustik di Laut Arafura. Jurnal Penelitian Sains. 13(1): 13106.

Harjanti R, Pramonowibowo, Hapsari TD. 2012. Analisis musim penangkapan dan tingkat 
pemanfaatan ikan layur (Trichiurus $s p$ ) di Perairan Palabuhanratu, Sukabumi, Jawa Barat. Fisheries Resources Utilization Management Technology. 1(1):55-66.

Kar T K, Chakraborty K. 2009. Bioeconomic analysis of Maryland's Chesapeake Bay oyster fishery with reference to the optimal utilization and management of the resource. International Jurnal Of Engineering, Science and Technology. 1(1): 172-189.

Kekenusa JS. 2008. Evaluasi model produksi surplus ikan cakalang yang tertangkap di Perairansekitar Bitung Provinsi Sulawesi Utara. Jurnal SIGMA. 11(1): 43-52.

Khoiriya N. 2010. Ekologi-ekonomi efek pemutihan karang (coral bleaching) terhadap sumberdaya ikan (studi kasus Taman Nasional Karimujawa, Provinsi Jawa Tengah) [Tesis]. Sekolah Pascasarjana, Institut Pertanian Bogor. Bogor.

Kuriakose S, K G Mini. 2006. A stochastic model to analyse pelagic fishery resource dominance along the Karnataka Coast (West Coast of India). Indian Journal of Marine Sciences. 35(3): 257-262.

Mehanna S F. 2001. Population dynamics and fisheries management of the indian mackerel Rastrelliger kanagurta in the Gulf of Suez, Egypt. National Institute of Oceanography and Fisheries. 12 : 217229.
Panayotou T. 1982. Management Concepts for Small-scale Fisheries, Economic and Social aspect. FAO Fisheries Technical Paper 228. 53p.

Saanin H. 1984. Taksonomi dan kunci identifikasi ikan (jilid I dan jilid II). Bandung: Bona cipta. $516 \mathrm{p}$.

Stregiou KI. 2000. Overfishing, tropicalization of fish stocks, uncertainty and ecosystem management: resharpening Ockham's razor. Journal of Fisheries Research.55: $1-9$.

Sulistiono. 2006. Kematangan gonad dan kebiasaan makanan ikan janjan bersisik Parapocryptes sp. di Perairan Ujung Pangkah, Jawa Timur. Jurnal IImu-ilmu Perairan dan Perikanan Indonesia. 13 (2): 83-175.

Utami, Gumilar, Sriati. 2012. Analisis bioekonomi penangkapan ikan layur (Trichirus sp.) di perairan Parigi Kabupaten Ciamis. Perikanan dan Kelautan. 3(3): 137-144.

Yusuf M, Sutrisno S, Luky A. 2007. Analisis pengelolaan sumberdaya ikan merah (Lutjanus spp.) di Kepulauan Spermonde Sulawesi Selatan. Jurnal IImu-ilmu Perairan dan Perikanan Indonesia. 14 (2):115-124. 